\title{
Reversal Theory-Based Sport and Exercise Research: A Narrative review
}

\author{
Joanne Hudson ${ }^{1}$ Jonathan R. Males ${ }^{2}$ \& John H. Kerr ${ }^{3}$ \\ ${ }^{1}$ Swansea University, Wales; ${ }^{2}$ Performance1, England; ${ }^{3}$ University of British Columbia, Canada
}

Date of submission 15/6/2016

Correspondence should be addressed to John H. Kerr, Ph.D. at johnkerrsportpsych@ gmail.com 


\section{REVERSAL THEORY RESEARCH}

Although reversal theory (RT; Apter, 1982, 2001) has been applied to a wide range of topics in

3 psychology, it is sport and exercise that has received the most attention from researchers. Other topics

4 include, but are not restricted to smoking cessation (e.g., Cook, Gerkovich, O’Connell, \& Potocky,

5 1995), delinquent and hooligan behaviour (e.g., Jones \& Heskin, 1988; Kerr \& de Kock, 2002),

6 addictions (e.g., Brown, 2001), psychotherapy (e.g., Wilson \& Wilson, 1996), leadership development

7 (e.g., Carter \& Davies, 2004), violence (e.g., Howard, 2011), risk-taking (e.g., Trimpop, Kerr, \&

8 Kirkcaldy, 1999), espionage (e.g., Wilson, 2012), humour (e.g., Downing, 2000; Murgatroyd,1987),

9 design (e.g., Fokkinga \& Desmet, 2012), and sexual behaviour (e.g., Gerkovich, 1997; Vera-Cruz,

10 Vinsonneau, \& Mullet, 2010). The research focus on sport and exercise may be because it offers a

11 unique context for research which is different from the other domains in which RT has been applied

12 (e.g., immediacy, inherent competition, performance outcomes, varying levels of expertise and

13 experience). Sport and exercise are actually two different research areas. However, they are considered

14 together in this review because both involve performance to some degree. In the majority of the

15 research studies reviewed here, both athletes and exercisers have accepted a personal and/or team

16 challenge, and have a strong desire to be successful and perform as well as possible, whether that is

17 measured against opponents or their own standards.

In 1985, the first journal manuscript on reversal theory (RT) and sport was published in the

19 Journal of Sport Sciences. That paper applied the theory's "trademark" X-curve relationship between

20 arousal and hedonic tone to the experience of arousal in sport (Kerr, 1985). In the 30-year period since

21 that publication appeared, RT (Apter, 1982, 2001) has grown from its original insights to become more

22 complex and possibly daunting to some newcomers. In this period, the theory has been used as a

23 theoretical foundation for studies exploring research questions across the full palette of topics in sport 


\section{REVERSAL THEORY RESEARCH}

24 and exercise psychology (see e.g., Kerr, 1991, 1997, 2001; Kerr, Lindner, \& Blaydon, 2007).

25 Consequently, because of: (a) the gradual development of reversal theory from its early beginnings; (b)

26 the increasing complexity of the theory; (c) the unique context; and (d) a diverse and expanding

27 literature base reflecting a critical mass of sport and exercise research work, a review would appear to

28 be timely. Such a review would, not only summarise RT research results to date, but also highlight

29 successful RT research strategies, techniques and procedures, acting as a kind of "research test bed"

30 potentially beneficial to both sport and exercise psychologists and psychologists working in other

31 psychology domains.

It was the aim of this comprehensive review to critically scrutinize peer-reviewed journal

33 publications on reversal theory sport and exercise research from 1985-2014. A combined

34 systematic/narrative approach was adopted, similar to that used by, for example, Rice et al. (2016) in

35 their review of mental health in elite athletes. Systematic searches ensure that all articles published

36 within a certain time-span are identified. In the present review, the types of databases searched and the

37 criteria for the inclusion of research publications found during those searches are reported (see Method

38 section). Narrative reviews can make connections between diverse research articles, allowing

39 integrations and possible reinterpretations, as well as providing a useful overview of a topic. In

40 addition, narrative reviews can suggest broader, higher-level theoretical conclusions, beyond those

41 possible in individual research reports and thus these may draw attention to weaknesses, gaps in the

42 literature and contradictions where necessary (Baumeister \& Leary, 1997). For example, in the present

43 review the authors comment on the strengths or weaknesses of methodologies used in particular

44 research studies where this was considered central to the discussion. However, in spite of these

45 advantages, care must be taken to guard against possible bias in narrative reviews. 


\section{REVERSAL THEORY RESEARCH}

47 is provided in the following section. Where relevant, brief comparisons are made with other theories.

48 An overview of RT is necessary to identify its most relevant elements and inform readers'

49 understanding of the core research questions or propositions that emerge in the Method section. If

50 readers are to make sense of the review, it is crucial that they understand basic RT concepts, such as

51 motivational states and dominance, their possible relationship with performance, and the motivational

52 reversal process itself.

\section{Reversal Theory Explained}

RT's basic premise is that people's motivations and emotions are inherently inconsistent, but

that there is a pattern to this inconsistency. The theory posits a framework of eight bistable motivational

states. Motivational states operate in pairs and as reversals take place, an individual's motivation and

57 felt experience changes. The eight motivational states, arranged in four bistable pairs, are outlined

58 below:

\section{Four Somatic Motivational States}

In the serious (telic) and playful (paratelic) motivational states any activity is experienced in

61 two contrasting ways. In the serious state, an individual prefers activities that are perceived to be

62 significant and have meaning beyond their immediate fulfilment (e.g., achieving training goals prior to

63 an important competition). In the playful state, activities tend to be unplanned, spontaneous, and

64 concerned with immediate pleasure (e.g., a "lap of honour" around the arena by athletes after victory in an Olympic final). The negativistic and conformist states are oriented around the individual's response to implicit or explicit rules. In the conformist state, an individual's experience is oriented around the value of belonging, of "fitting in" to the prevailing norms and meeting social expectations. Behaviour is likely to be compliant, dutiful, and obedient (e.g., when a new player joins a national team training camp). In contrast, the negativistic state is one in which an individual's experience is oriented around a 


\section{REVERSAL THEORY RESEARCH}

71 prefer to "go against the flow" (e.g., when a player breaks a team curfew before an important game).

\section{Four Transactional Motivational States}

In the mastery state, a person values and seeks power, control, and toughness. This state

underpins competition and a desire to win (e.g., facing a competent opponent in a Judo competition). In

75 the sympathy state, a person values cooperation and harmony with others and is sensitive and kind

76 (e.g., helping an opposition player who has been injured). The experience of pleasure comes from

77 perceived outcome, in terms of gaining or losing in transactions with other people or objects. In the

78 self-focused state (autic), one gains pleasure or displeasure from what happens to oneself. There is a

79 high value on individuality (e.g., receiving a medal at a major tournament). Conversely, in the other-

80 focused state (alloic), pleasure or displeasure depends on the experience of others. There is a high value

81 in transcendence, going beyond one's individual identity (e.g., empathising with the players in your

82 favourite soccer team who have just lost a cup final in a penalty shootout).

Felt arousal is how worked-up or emotionally intense a person feels about what he or she is

doing and is an important concept in RT. The experience of felt arousal is fundamentally different in the serious and playful states. In the serious state, high levels of felt arousal are unpleasant and perceived as a form of anxiety or tension. Low levels of arousal are preferred and likely to be experienced as pleasant relaxation or calmness. Pleasure comes from resolving any "tension" associated with an uncompleted task. In the playful state, high felt arousal is enjoyable, being experienced as excitement, joy, or exhilaration. By contrast, low arousal in the playful state is experienced as unpleasant boredom. In the sport psychology literature, Jones (1995) criticised RT for using an undifferentiated

91 model of arousal, rather than a multi-dimensional model with separate somatic and cognitive

92 components. The multi-dimensional anxiety model originally comprised a three-factor model of 93 cognitive anxiety, somatic anxiety, and self-confidence (Martens, Burton, Vealey, Bump, \& Smith, 94 1990). It has since been developed to include a facilitative and debilitative interpretation of anxiety 


\section{REVERSAL THEORY RESEARCH}

95 (e.g., Hanton, Wadey, \& Connaughton, 2005; Jones \& Hanton, 2001). The essence of Jones' (1995)

96 criticism was that RT does not explicitly acknowledge the same three dimensions as the multi-

97 dimensional model. This criticism fails to take into account the phenomenological basis of felt arousal

98 within RT, which is not the same as physiological activation. RT offers a more elegant explanation for

99 how and why the experience of anxiety can be helpful or not, because the interpretation of felt arousal

100 can be pleasant or unpleasant depending on the operative motivational state.

\section{Motivational States and Emotions}

Sixteen primary emotions are produced by different combinations of motivational states (see

103 Table 1). Positive, pleasant emotions result when a person's preferred way of feeling matches their

104 current experience. Negative, unpleasant emotions occur when there is a mismatch between a person's

105 preferred way of feeling and their current experience.

106 Somatic emotions. The theory suggests that the serious-playful and negativism- conformist

107 pairs operate in combination. This leads to the experience of eight possible emotions. These are termed

108 somatic emotions because they all relate to the experience of felt arousal. The emotions will either be

109 pleasant or unpleasant depending on the prevailing state combination. An individual's emotions are

110 posited to change in two ways: first, through their own actions to manage their level of felt arousal.

111 When the serious and conformist states are operative, attempts will be made by the individual to

112 decrease felt arousal. When the playful and negativistic states are operative, attempts will be made to

113 increase or prolong high felt arousal. Second, emotions can change when there is a reversal from one

114 state combination to another, so that the prevailing level of felt arousal is experienced in a different

115 way.

116 Transactional emotions. These are termed transactional emotions because they all relate to the

117 experience of felt transactional outcome, which is based on the perceived outcome (pleasant gain or

118 unpleasant loss) in transactions with other people or objects. Working in combination, the mastery- 


\section{REVERSAL THEORY RESEARCH}

119 sympathy and self- and other-focused motivational states allow for a range of transactional emotions.

120 For example, when the self-focused and mastery states are operative, high levels of felt transactional

121 outcome are pleasantly experienced as pride, but low levels would be experienced as unpleasant

122 humiliation. A reversal from the self- to the other-focused state would result in the experience of

123 pleasant modesty or unpleasant shame, depending on the level of felt transactional outcome.

RT provides a single primary emotion for each of the sixteen possible state combinations, even

though each combination has the potential to host a range of emotions of the same family. For example,

126 love could be considered to be an emotion arising from the other-focused-sympathy combination. This

127 can lead to problems if the specific example given is an unfamiliar emotion (e.g., sullenness, virtue). A

128 related concern is the contrast between the precision of the theory's basic structure of eight bistable

129 states, and the fluid nature of self-awareness. As Ekman (1999, p. 55) states: "It is no easy matter to

130 assess subjective experience, especially if what is wanted is something more than the amount of

131 positive or negative emotion.” Also, people vary widely in their ability to name and express emotions

132 (John \& Gross, 2004). It could be argued that some emotions within the RT model do not form a

133 recognisable regular component of everyone's emotional landscape. To counter both of these criticisms,

134 RT proponents have developed rich lexicons to describe the many relevant emotions that are salient to

135 specific groups and situations (e.g., Potocky, Cook, \& O’Connell, 1993). However, some concern

136 remains that RT emotions, such as sullenness or placidity, may not be readily recognised by

137 individuals.

138 Furthermore, in contrast to theories that suggest that emotions arise as the result of appraisals of

139 environmental conditions (e.g., Campo, et al., 2012; Lazarus, 2000; Lazarus \& Folkman, 1984), RT

140 begins with the premise that people are at all times oriented towards achieving core motivational values

141 (e.g., fun in the playful state). This is close to Ekman's (1990) category of theories of emotion that are

142 oriented toward fundamental life tasks, or Frijda's $(1986,1994)$ proposition that emotion serves as an 


\section{REVERSAL THEORY RESEARCH}

143 early warning system for evolutionary survival. RT proposes that emotions arise as a consequence of

144 the degree to which a core motivational value is being experienced. This can be considered a form of

145 appraisal, but it is framed within the parameters of the prevailing motivational states.

\section{Stress}

147 Healthy functioning in RT terms requires adequate motivational flexibility to experience all the

148 different combinations of motivational states as and when appropriate (Apter, 2001). Negative emotions

149 are indicative of stress and prolonged experience of negative emotions may affect a person's health and

150 psychological well-being. Apter and Svebak (1989) proposed two fundamentally different types of

151 stress within RT. Tension-stress refers to feelings that arise when a person perceives a discrepancy

152 between the preferred and actual level of a salient motivational variable (e.g., felt arousal). For

153 example, in relation to the serious state, there is a preference for low felt arousal. High felt arousal is

154 not preferred and will lead to tension-stress, experienced as anxiety or worry. A lack of control or

155 weakness when in the self-focused-mastery state will lead to tension-stress experienced as humiliation.

156 Therefore, stress as a result of "tension" can take many forms, depending on the operative motivational

157 state combination and will be experienced as an unpleasant emotion. Effort-stress is the feeling of effort

158 made to reduce tension-stress. This has a subjective meaning and is not necessarily linked to the degree

159 of physical activation or exertion. It can be expressed externally, in an attempt to change external

160 factors, or internally, in response to internal factors.

\section{The Process of Psychological Reversals}

The theory suggests that there are three types of causal factors that can trigger a reversal from

163 one state to its opposite pair. First, a change in the environmental situation, or a specific, relevant

164 external event can trigger a reversal. Second, if a person's needs in a particular motivational state are

165 not met over an extended period, a reversal to the opposite state can occur as a result of frustration.

166 Third, irrespective of any external force, reversals will naturally occur over time, due to satiation. 


\section{REVERSAL THEORY RESEARCH}

167 Individuals vary in how easily and frequently they reverse between states (motivational flexibility or 168 lability).

169 In addition, individual differences affect the patterns of reversals and preference for one state

170 over another. This is termed motivational dominance in RT and is the innate bias held by a person to

171 spend time in one state over another in the same motivational pair. It is therefore possible to describe an

172 individual's personality in terms of their dominance (e.g., mastery dominant, negativistic dominant).

173 Apter (2001) argues that dominance differs from a personality "trait" because it is possible for someone

174 to possess a particular dominance, but still spend some time in the opposite state. By contrast, trait-

175 based personality theories measure the degree to which an individual's preferred behaviour lies along a

176 continuous, normalised scale. Individual personality is described by the strength and frequency of how

177 a particular trait, such as neuroticism, is displayed (e.g., Nettle, 2007).

RT sport and exercise research has included a variety of both quantitative and qualitative

179 research techniques and tools that have been used to tap into the experience of individuals in different

180 circumstances and situations in sport and exercise. For example, RT quantitative research has included

181 surveys, laboratory and field experiments, field studies and real-life simulations, using established

182 measures of motivational state and dominance, and emotion, stress and effort. Situation-specific,

183 custom-designed questionnaires, objective indices of motivational state, and psychophysiological

184 measures have also been utilised. Qualitative research has focused on competitive and non-competitive sport and exercise events. The majority have been field or case studies using semi-structured interviews with participants, or have used autoethnography. In some cases, quantitative and qualitative methods were combined.

The plethora of methods and approaches previously used in reversal theory sport and exercise research justifies the use of a narrative review as the most meaningful way to make sense of the results 


\section{REVERSAL THEORY RESEARCH}

191 about previous research, such as the early concentration on the serious-playful (telic-paratelic) pair of

192 states; the mastery state as a largely unexplored factor in performance; challenges in identifying and

193 measuring reversals; and the nature of ongoing changes in motivational state as events proceed. These

194 and other concerns are addressed in the present review.

\section{Method}

\section{Search Strategy}

General computer databases, Sportdiscus, PsychINFO, PubMed, and Google Scholar were

searched for all English language, peer-reviewed articles that featured sport or exercise research studies

199

that used reversal theory (1985-2014). The search terms used were combinations of sport or exercise and key words related to RT, including reversal theory, reversal(s), (meta)motivational state,

(meta)motivational dominance, felt arousal, somatic emotions, transactional emotions, tension stress,

effort stress, as well as the terms for individual motivational states (e.g., telic state, mastery state). In addition, sport and exercise studies, found on the RT publications database (www.reversaltheory.org), retrieved from journal publication reference lists, and any other published studies known to the authors were also included. Theoretical journal manuscripts, books, theses, dissertations, and conference abstracts and proceedings were excluded. All the published studies identified were included in the present review, thus eliminating any possible selection bias. This produced a total of 56 reversal theory-based studies. For sport, there were 15 studies examining athletes' personality dominance characteristics, two on aggression, nine on adventure or risk sports, one on injury rehabilitation, and 17

210 field studies involving competing athletes. For exercise, there were five field and five laboratory

211 studies. Two studies examined motor skill and performance. To facilitate understanding, the studies identified in the review were divided thematically using

213 broad inclusion criteria based on three basic assumptions, or pillars of the theory itself (e.g., the

214 reversal process), and an ever-present topic from within the body of sport and exercise research in 


\section{REVERSAL THEORY RESEARCH}

215 general (i.e., mental state and optimal performance). These themes represent core research questions or

216 propositions explored in the identified RT studies. Some studies present evidence related to more than

217 one theme. The four themes which provide structure to this review were:

218 1. Evidence that the full range of motivational states have been reported in sporting contexts and that

219 these constructs provide a valid description of athletes' experience across different phases of

220 competition, in different types of sport, and in both individual and team events.

221 2. Evidence supporting the reversal process and its causal factors, providing a theoretically coherent

222 explanation as to how and why change occurs in a performer's emotional and motivational experience.

223 3. Evidence for the role of motivational dominance in preference for, and participation in different

224 types of sport. Thus, providing a basis for understanding individual differences in personality.

225 4. Evidence for a definite relationship between motivational state and performance, providing a 226 means of optimising competitive performance.

227 The final summary paragraph of each theme presents a critical analysis of current knowledge,

228 limitations, strengths, or future directions within that theme.

\section{Evidence of the Full Range of Motivational States in Sporting Contexts}

A series of research studies that have explored the role of the motivational states in sport

231 performance included international level individual athletes in slalom kayaking (Males, 1999; Males \&

232 Kerr, 1996; Males, Kerr, \& Gerkovich, 1998), and national level team players in volleyball (Males,

233 Kerr, Thatcher \& Bellew, 2006) and lacrosse (Kerr \& Males, 2010, 2011). These studies used high-

234 level athletes in naturalistic settings to provide detailed data collected over an extended time period. In

235 the case of the slalom kayaking studies, this comprised a complete competitive season of domestic and

236 international events, and over major tournaments for volleyball and lacrosse.

\section{Slalom Kayaking Studies}

238 These slalom kayaking studies focused on the athletes' experiences in pre-event, during 


\section{REVERSAL THEORY RESEARCH}

239 competition and post-event time periods. The results of quantitative and qualitative studies (Males \&

240 Kerr, 1996; Males, Kerr, \& Gerkovich, 1998) showed that individual competitors reported all four

241 somatic motivational states (serious, playful, conformity, negativism). The actual proportions varied

242 between individual athletes, as RT would predict. Serious-conformity was the most frequently reported

243 combination, occurring in over $70 \%$ of coding units pre-race, just under $60 \%$ during the race runs, and

244 increasing to $84 \%$ between race runs. Playful-conformity was the next most frequently reported

245 combination, most often reported during performance (35\%) and least often in the post-race period

246 (4.1\%). Negativism, in either the playful or serious combination, mainly occurred post-race, but

247 infrequently. In terms of the transactional emotions, these individual athletes reported self-focused-

248 mastery as their predominant state, with only isolated examples of self-focused or other-focused-

249 sympathy. The authors claimed that these examples occurred in the type of situations that RT would

250 predict, for example at times when a competitor needed to seek rest or medical treatment (self-focused-

251 sympathy), or briefly when expressing concern for those who had not qualified for the national team

252 (other-focused-sympathy). The other-focused-mastery state combination, representing a desire to help

253 others experience control, was not reported amongst the elite slalom kayakers in this study.

254 Volleyball and Lacrosse Studies

255 The volleyball and lacrosse studies (Kerr \& Males, 2010, 2011; Males et al., 2006) presented

256 qualitative data using a thematic approach. The aim was to explore how motivational states might relate

257 to coaching style, team communication, reactions to substitution, and responses to game outcomes.

258 Post-game interviews in volleyball and lacrosse environments also showed a range of motivational

259 state combinations, before, during, and after competition (Kerr \& Males, 2010, 2011; Males, et al.,

260 2006). Transactional emotions and the underpinning motivational states were salient in these team

261 contexts. For example, the other-focused-mastery state combination was less frequently reported by

262 volleyball players in a poorly performing team than the self-focused-mastery combination. Team 


\section{REVERSAL THEORY RESEARCH}

263 cooperation and cohesion appeared to suffer as a result. The results also provided insights into

264 individual differences in motivation, suggesting that the players were likely to require very different

265 performance strategies to maintain their preferred level and type of emotional focus during

266 competition.

267 In other research, Thatcher, Kerr, Amies, and Day (2007) examined intra-individual responses

268 to injury by mapping operative motivational state combinations in athletes during sports injury

269 rehabilitation. The results suggested that a prevailing state combination of serious-conformist self-

270 focussed-mastery over time appeared to assist athletes in successfully completing their rehabilitation.

271 More recently, Houge Mackenzie's work extended the use of qualitative and quantitative methods in RT

272 research to adventure sports participants (Houge Mackenzie, Hodge, \& Boyes, 2010, 2011, 2013;

273 Houge Mackenzie \& Kerr, 2012, 2014; Kerr \& Houge Mackenzie, 2012, 2014). Among other findings,

274 these studies showed the multifaceted nature of adventure sports motivation, which could be attributed

275 to a variety of different operative motivational state combinations and identified the existence of a

276 multi-phasic relationship between flow experience (e.g., Csikszentmihalyi, 1975) and motivational

277 reversals (serious (telic) flow and playful (paratelic) flow).

\section{Critical Summary}

279 Taken together, these studies represent data from athletes and sport participants of differing

280 ability when competing, or during recreation. The quantitative and qualitative findings provided useful

281 evidence for the existence of a range of motivational states in both individual and team sports. The

282 results also showed that different motivational states can be operative at different times during the

283 course of an event, and that some states are experienced less frequently than others. In view of criticism

284 that the reasons for reversals in sport are poorly understood (Balague, 2005), it would be useful to

285 know from future research how, and for what reasons, performers' motivational states change (or not)

286 during the course of an event. The next section examines research on motivational reversals in sport 


\section{REVERSAL THEORY RESEARCH}

287 and exercise.

\section{Motivational Reversals in Sport}

Early evidence for the reversal phenomenon in a sporting context came from an exercise study

using objective indices (Kerr \& Vlaswinkel, 1993: see also Kerr \& van den Wollenberg, 1997). Arousal preference (a defining feature of the serious and playful states) was assessed based on colour choices made by recreational runners throughout the duration of a run. Preference for the colour red has been linked to the arousal-seeking playful state and preference for light blue to the arousal-avoiding serious state (Walters, Apter, \& Svebak, 1982). Participant runners in the study were required to choose between a red or light blue card (as an indicator of their arousal preference and therefore their operative motivational state) at regular points during the run. The results indicated a pattern of extreme shifts in colour preference and state consistent with RT reversal constructs. For example, fast runners started the run in the serious state and reversed to the playful state at some point during the run, while slow females remained playful throughout the run (generally, RT does not predict differences between males 300 and females). Hudson and Bates (2000) identified reversals between the serious and playful states during a dart-throwing task. Participants were free to choose between two versions of the task within a tenminute period. In the serious version, participants were required to achieve a randomly selected score with one set of three darts. A cash bonus was awarded each time the score was achieved. This task was intended to enable participants to plan their actions, adopt a serious state of mind, and engage in the activity for a specific purpose. In the playful version, a target score was again randomly selected for each set of three throws, but it was not conveyed to the participants, so they were throwing for an unknown outcome. Quantitative data was collected using an RT state measure, the Telic/Paratelic State Inventory (TPSI; Cook, Gerkovich, Potocky, \& O’Connell, 1993), and participants were invited to 


\section{REVERSAL THEORY RESEARCH}

311 no reversals, four remained for the whole trial with the serious task and one with the playful task. The

312 remaining 11 participants made between one and four reversals within 10 minutes. The reasons given

313 for changing tasks were categorised into four themes, "desire for a goal" and "lack of success" (taken

314 as evidence of frustration as the causal factor) and "boredom" and "no explanation" (taken as evidence

315 of satiation). The lack of evidence for contingent events was explained by the closed environment of a

316 laboratory task.

\section{Naturalistic and Competitive Environments}

318 Research in more naturalistic and competitive environments has also found evidence for

319 reversals. Bellew and Thatcher (2002) examined motivational state changes between the serious and

320 playful states in 20 male rugby players over three matches.Participants completed the State of Mind

321 Indicator For Athletes (SOMIFA; Kerr \& Apter, 1999) between 30 and 90 minutes after each match and

322 recorded key incidents that had occurred during the game, the time the incident occurred and any short

323 or long term effects on their behaviour or goals. Matches were video-recorded, and two days after each

324 match participants reviewed the video in an individual interview. At each of the key incidents, the

325 researcher paused the video, questioned the participant in more detail and collected TSM (Telic State

326 Measure; Svebak \& Murgatroyd, 1985) responses. All participants reported reversals across the three

327 matches. The number of reversals for each participant ranged from 1 to 10, which can be taken as

328 support for individual variation in the propensity to reverse (lability). A total of 22 reversals were

329 identified, 12 serious to playful and 10 playful to serious. Sixteen were due to a contingent event, 2 to

330 frustration, and 4 to a combination of these two factors. None were due to satiation. The authors

331 pointed out that, while the study focused on the serious and playful state reversals, some of the

332 examples given in interviews pointed to the salience of other motivational states during competition.

333 Qualitative RT-based studies (Grange \& Kerr, 2010; Kerr \& Males, 2011) have specifically

334 examined the motivation behind aggressive and violent actions in contact sports (e.g., lacrosse, 


\section{REVERSAL THEORY RESEARCH}

335 Australian football). The results confirmed the role that reversals can play in these incidents. The

336 authors pointed out that when playing these sports elite athletes generally have the playful-mastery state

337 combination operative. However, under certain conditions, reversals can occur to serious-mastery,

338 serious-negativism or playful-negativism state combinations, bringing about aggressive and violent acts

339 concerned with demonstrating power (serious-mastery), exhibiting anger (serious-negativism), and

340 experiencing thrill (playful-negativism), respectively.

341 An examination of reversals across all eight motivational states was carried out in a case study

342 analysis of five male golfers taking part in a round-robin tournament (Hudson \& Walker, 2002). Using

343 post-event interviews based on the Motivational State Coding Schedule (Potocky, Cook, \& O'Connell,

344 1993) and content analysis, they found evidence for all three reversal inducing factors, with 17 reported

345 reversals in total. The authors found 17 reported reversals. Of these, contingent events accounted for 11

$346(65 \%)$, frustration for $5(29 \%)$ and satiation for $1(6 \%)$. The authors were able to link reversals to

347 participants' key moments in play across the tournament.

348 In the Kayaking study mentioned earlier which used post-event interviews (Males et al., 1998),

349 contingent events (usually an error during the race), were found to precipitate reversals in slalom

350 kayakers' motivational states. Males et al. (2006) also provided evidence that volleyball players

351 experienced changing motivational patterns and reversals throughout a tournament. All three causal

352 factors were identified, triggering reversals across state combinations. For example, the coach's

353 behaviour triggered a reversal from the conformist to negativistic state in one player. For another

354 player, the coach's failure to "substitute him on", when a team-mate was performing poorly, caused a

355 reversal from other-focused-sympathy to self-focused-sympathy as a result of his frustration.

Kerr and Kuk (2001) conducted a field experiment where recreational runners completed

357 theTension and Effort Stress Inventory (TESI; Svebak, 1993) pre- and post- high and low intensity

358 running on outdoor trails. Half completed a $5.0 \mathrm{~km}$ run and half a $1.7 \mathrm{~km}$ run. The researchers argued 


\section{REVERSAL THEORY RESEARCH}

359 that, while it is possible to use the TESI as a straightforward measure of emotions and stress, The

360 researchers argued that, while it is possible to use the TESI as a straightforward measure of stress, it is

361 also possible to link changes in individual emotions with reversals in motivational states. Among the

362 results they obtained, for pre-to post-running $5.0 \mathrm{~km}$, was a significant increase in total pleasant

363 emotions and a significant decrease in total unpleasant emotions, suggesting that a number of runners

364 reversed during the run. Furthermore, Kerr et al. (2006) compared recreational and competitive runners

365 under laboratory and natural conditions and found that changes in some individual TESI emotions

366 reflected particular motivational state reversals. For example, for somatic emotions in recreational

367 runners, significant increases in excitement (playful-conformist) and decreases in anxiety (serious-

368 conformist) found pre- to post-running, were indicative of serious to playful reversals. Also, for

369 transactional emotions in recreational runners, significant decreases in shame (other-focused-mastery)

370 pre-to post-running and increases in pride (self-focused-mastery) post-running were indicative of other-

371 focused to self-focused state reversals. Other RT sport or exercise studies that found positive changes in

372 emotions and stress (indicative of reversals), include three studies that examined recreational

373 participation in aerobics, circuit training, and Tai Chi (Frith, Kerr, \& Wilson, 2011), baseball

374 (Fujiyama, Wilson, \& Kerr, 2005), and tennis (Kerr, Fujiyama, \& Campano, 2002).

375 Not all studies have provided evidence of reversals. Thatcher, Reeves, Dorling, and Palmer

376 (2003) found no significant differences in motivational state amongst 23 experienced skydivers, who

377 completed the TPSI and TESI 15 minutes pre-jump and 15 minutes post-jump.

\section{Critical Summary}

379 Elite and recreational level, individual and team competitors reported rapid changes in their

380 emotional and motivational state that can be explained by RT's concept of reversals. Therefore, there is

381 research evidence to confirm that reversals occur in sport and exercise, and that they do so for the

382 reasons suggested by the theory (environmental events or settings, frustration, and satiation). On the 


\section{REVERSAL THEORY RESEARCH}

383 positive side, in reading through the interview transcripts from those qualitative studies described

384 above, Apter and Heskin (2001) pointed out that it was possible to follow the reversals that occurred in

385 response to the changing situations that confronted the athletes in a realistic and meaningful way.

386 However, on the negative side, identifying and measuring reversals can be challenging. Some research

387 on reversals, described above, has dealt with this challenge by using questionnaires that attempted to

388 objectify experiential states and measure them on linear scales. This approach was only partially

389 successful, as it failed to maximise the theory's potential to capture the subtleties and variety of

390 individual meaning and experience. Also, some studies were limited because they only considered the

391 serious and playful states and did not address other motivational states.

\section{The Role of Motivational Dominance in Sport Preference and Participation}

The third research theme to be explored is the evidence for a relationship between motivational

394 state dominance (how much time is spent in one state compared to its opposite) and choice of sport. In

early RT research, motivational dominance studies focused on the serious-playful and negativism-

conformity dimensions because the Telic Dominance Scale (TDS; Murgatroyd, Rushton, Apter, \& Ray, 1978) and the Negativism Dominance Scale (NDS; McDermott \& Apter, 1988) were the only measures

398 that had been developed at that time.

Research has shown that serious dominant individuals are more likely to choose safe and/or endurance-based sports, such as long-distance running, while playful dominant individuals are more

401 likely to participate in risk and/or explosive sports such as surfing or rock-climbing (e.g., Kerr 1991;

402 Kerr \& Svebak, 1989; Svebak \& Kerr, 1989). This is most strongly identified through responses to the

403 arousal-avoidance dimension of the TDS. Trimpop, Kerr, and Kirkcaldy (1999) found a positive

404 correlation between TDS arousal seeking and Zuckerman's Sensation Seeking Scale (Zuckerman, 405 1979) that has been widely used to investigate participation in high-risk activities. NDS proactive 406 negativism scores, along with TDS high arousal seeking and low serious-mindedness scores, pointed to 


\section{REVERSAL THEORY RESEARCH}

407 increased participation and injury in the high-risk sport of snowboarding (Cogan \& Brown, 1999; see

408 also Chirivella \& Martinez, 1994).

Motivational dominance also relates to level of participation in sport. Professional athletes

410 reported higher levels of serious dominance than less committed or amateur athletes (Kerr, 1987).

411 Serious dominance brings an ability to plan ahead, be serious-minded and focused on long-term goals.

412 In addition, Vlaswinkel and Kerr (1990) found no difference in NDS scores between recreational and

413 professional soccer players, while Braathen and Svebak (1990) found that skilled explosive sport

414 performers scored significantly higher on the NDS Reactive Negativism scale than endurance and team

415 sport athletes. In 1998 it became possible to assess an individual's dominance across all four pairs of

416 states and show which state is salient using the Motivational Style Profile (MSP; Apter, Mallows, \&

417 Williams, 1998). Studies employing this measure, and therefore assessing a greater array of

418 dominances, are discussed below.

\section{The Hong Kong Sport Participation Studies}

Adding to the evidence linking motivational dominance with motives for taking part or not

421 taking part in sport and physical activity were results obtained from large samples of Hong Kong

422 students by Lindner and his colleagues (Lindner \& Kerr, 2000, 2001; Kerr, Au, \& Lindner, 2004). In

423 the first study, new university entrants responded to a survey questionnaire in which motives for

424 participation or non-participation were phrased in terms of reversal theory's eight motivational

425 categories (Lindner \& Kerr, 2000). Questionnaire responses were then used to classify respondents

426 according to their primary sport participation or non-participation motivational orientation (MO).

427 Significant differences between participants and non-participants were found, in addition to some

428 significant gender differences. The serious and other-focused MOs were most frequently rated by

429 participants. For non-participants, the playful, serious, mastery and self-focused MOs were rated most

430 frequently. In the second study (Lindner\& Kerr, 2001), for samples of (a) school children and youth, 


\section{REVERSAL THEORY RESEARCH}

431 and (b) university students, sport participation motivation was found to be weakly, but reliably

432 predicted by motivational dominance scores.

433 The third study (Kerr, Au, \&Lindner, 2004) explored a number of factors related to

434 participation, including whether student participants in sport and physical activities involving varying

435 levels of risk differ in their situational dominance. Situational dominance is a particular form of

436 motivational dominance relating to the amount of time a person spends in one state rather than its

437 opposite in particular situations, for example, regular participation in a particular sport. Respondents

438 who completed a modified version of the MSP were grouped, on the basis of their main sport or

439 physical activity, as being relatively low, medium, or high risk of physical injury. For male, high risk

440 participants, situational dominances were significantly less serious, arousal avoiding, and conformist

441 than their low risk counterparts. For females, situational dominance scores were found to be similar for

442 all three risk groups. The results of these three Hong Kong-based studies were used by the university

443 physical education department to help decide on the provision of a range of sport and exercise activities

444 which would be attractive to students with different dominance profiles.

445 Svebak's Model of Dominance, Muscle Composition and Type of Sport

446 Svebak $(1990,1999)$ offered an explanation for these sport participation patterns that integrated

447 the results from a series of psychophysiological studies into a model of personality and sports

448 participation (Braathen \& Svebak, 1990, 1994; Svebak, 1984, 1986; Svebak, Howard, \& Rimehaug,

449 1987; Svebak, Storjfell, \& Dalen, 1982). This model combined motivational dominance, muscle

450 composition and the demand characteristics of the sport. His conclusions were that, individuals who are

451 serious-dominant, have a greater proportion of slow-twitch muscle fibre and are more suited to

452 participation in endurance events, and individuals who are playful-dominant, have a greater proportion

453 of fast-twitch muscle fibres and are more suited to participation in explosive sports. Svebak's (1990)

454 model has been tested in a set of laboratory studies. For example, Legrand, Bertucci, and Thatcher 


\section{REVERSAL THEORY RESEARCH}

455 (2009; see also Legrand \& Thatcher, 2011), found that serious dominant runners felt significantly less

456 pleasure and greater perceived exertion than playful dominant runners after an explosive ten-minute

457 bout of intense treadmill running. Thatcher, Kuroda, Legrand, and Thatcher (2011) explored the

458 importance of a match between dominance and state using a cycle ergometer task. Participants' state

459 was manipulated by means of watching either a comedy (playful) or documentary (serious) film prior

460 to and during exercise. Playful dominant participants were more stressed than serious dominant

461 participants when exercising in the serious state and serious dominant participants were more stressed

462 than playful dominants when exercising in the playful state. Playful dominant participants also reported

463 greater discrepancy between internally reported stress and effort when exercising in the serious

464 compared with the playful state. Thus, the findings from this study partially supported Svebak's (1990)

465 model.

466 Thatcher, Kuroda, Thatcher, and Legrand (2010) also used a treadmill running task to test for

467 differences in motivational state, perceived exertion, attentional focus, heart rate, and oxygen

468 consumption (an index of higher workload) between serious and playful dominant participants. While,

469 there was no significant difference in the workload attained based on either dominance or state,

470 participants in a serious state reported greater perceived exertion at the end of a 30 minute run. Serious

471 state participants also paid more attention to their own body sensations (i.e., reported more associative

472 than dissociative thoughts) than participants in a playful state. In telic-dominant individuals preference

473 for congruence between state and dominance was demonstrated. These results also partially supported

474 aspects of Svebak's (1990) model.

475 In another laboratory study that used a similar methodology, EMG gradients (a physiological

476 correlate of task-focused behaviour) were observed in serious dominant participants regardless of

477 whether the serious or playful state had been induced before a leg flexion exercise task (Kuroda,

478 Thatcher, \& Thatcher, 2011). This finding contrasted with earlier research findings that suggested that 


\section{REVERSAL THEORY RESEARCH}

479 the EMG gradient was a marker for the serious state, not serious dominance (e.g., Apter \& Svebak,

480 1986; Rimehaug \& Svebak, 1987). Playful-dominant individuals performed better in the playful than

481 the serious state condition, whereas in the serious state condition, serious-dominant individuals

482 performed better than playful-dominant individuals. Although this difference wasn't significant, there

483 was a trend in this direction. Findings tended to support Svebak's (1990) model, in that outcomes are

484 more positive when metamotivational state and dominance are congruent.

485 Using a different approach, Kerr, Wilson, Svebak, and Kirkcaldy (2006) conducted a field study

486 to test the proposition that serious dominant individuals have a greater affinity and preference for

487 endurance sports than playful dominant individuals, who prefer explosive sports. The TDS was used to

488 divide university student participants into serious and playful dominance groups and the TESI state

489 version used to measure changes in emotion and stress completed before and after participation in an

490 endurance sport (long distance running) and an explosive sport (basketball). The results indicated that,

491 irrespective of the type of sport, participation consistently produced positive changes in emotional tone

492 with significant increases in excitement and decreases in anxiety, boredom, sullenness, modesty,

493 resentment, and guilt. There was no direct evidence that specifically linked the dominance groups to

494 either running or basketball, or to pre- to post-sport changes in emotions or stress.

\section{Motivational Dominance and Unhealthy Exercise Correlates}

In some instances, dominance characteristics in participants have been found to be associated

497 with unhealthy sport and exercise participation, including exercise dependence or addiction, and eating

498 disorders, such as anorexia nervosa and bulimia nervosa. Blaydon, Lindner, and Kerr (2002) found

499 dominance differences between triathletes classified as primary (exercise dependent only) or secondary

500 exercise dependent (exercise dependent plus an eating disorder), eating disorder, and no dependence or

501 disorder groups. MSP responses indicated that there were significant differences in dominance between

502 the exercise dependent and other groups. The secondary exercise dependent group was significantly 


\section{REVERSAL THEORY RESEARCH}

503 more serious dominant than the primaryexercise dependent group and both eating disordered groups

504 were significantly more mastery dominant than the non-dependent group.

505 Pain and Kerr (2004) reported the case study of a male high risk sport athlete who, in spite of

506 severe physical and mental damage, continued to participate in extreme sports. In one incident alone,

507 he had broken his back, broken and dislocated his right shoulder, broken four ribs which punctured

508 both lungs, and incurred serious brain damage. His scores on the TDS indicated that he was highly

509 playful dominant and this played the predominant role in his high risk sport motivational experience.

510 His interview comments indicated that he had become seriously dependent on high arousal sport

511 experiences, hence his strong motivation to continue participating in high risk sports in spite of further

512 danger to his health and wellbeing. The results of these studies indicate that some people have

513 dominance, or personality profiles that predispose them to taking physical risks through activities such

514 as sky diving or mountain climbing, others to take part in endurance events, such as long distance

515 running or triathlon. With committed and prolonged engagement with these activities, continued

516 participation at extreme levels may lead to dependence or addiction (Kerr, Lindner, \& Blaydon, 2007).

\section{Critical Summary}

518 Valid significant differences between motivational dominance groups were obtained in the early

519 dominance studies reported above. However, some critics might argue that the results were obtained

520 with newly-developed, general, rather than sport-specific measures, with minimal track record. In

521 addition, early studies were limited because the only measures available dealt with serious-playful and

522 negativism-conformity dominance. In some cases, the measures were used with relatively small

523 samples, with only a few attempts to replicate findings in subsequent studies. In contrast with early

524 dominance studies, the Hong Kong sport and exercise participation studies used large samples of

525 participants (>1500) and examined all RT motivational categories, which added to the importance of

526 the results obtained. Tightly controlled laboratory exercise studies have only been able to partially 


\section{REVERSAL THEORY RESEARCH}

527 support Svebak's $(1990,1999)$ contention that performance will be optimised when motivational

528 dominance, physiology, and type of sport are aligned. Thus, while Svebak's (1990) model is appealing

529 in its coherence, the evidence is still somewhat ambiguous.

The Relationship of Motivational States to Sport Performance

532 the work reviewed so far has shown that reversals occur before and during competition. This creates a

533 challenge when it comes to identifying the relationship between state and performance. The available

534 evidence that describes the motivational state combinations experienced during successful performance

535 is described below. Also, inferences based on studies that have investigated the experience of

536 unsuccessful or losing individuals and teams is drawn upon. Several studies have used non-competitive

537 and laboratory performance tasks and these are referred to where they offer additional insight.

Kerr and Cox $(1988,1990)$ explored the affective responses of male novice, average, and

539 skilled squash players who were set a series of target performance tasks in a standard squash court. The

540 TSM was completed prior to the first and after the second task. There were no differences in serious

541 state between the groups, but there was a trend for participants to become more serious from pre- to

542 post-task and a majority of participants from all groups were in a serious state during the task. This

543 study did not identify a direct relationship between motivational dominance or state and performance,

544 but it did point to differences in the way skilled squash players perceived the arousaldemands of the

545 task. Kerr extended this research by means of three simulated squash tournaments, so that affective

546 responses could be determined under ecologically valid conditions (Cox \& Kerr, 1989, 1990). A similar

547 battery of questionnaires, as used in the previous study, was administered to players before and after

548 each of four tournament games. A post-hoc separation of participants into most- and least-successful

549 players led to the creation of groups of winners and losers. The only significant group difference in

550 serious state scores occurred among losers after the second game (when they had lost the opportunity to 


\section{REVERSAL THEORY RESEARCH}

551 win the tournament); significantly more of them were in a playful than a serious state. In general, more

552 winners than losers were in a serious state before and after the tournament.

Perkins, Wilson, and Kerr (2001) tested maximal performance on a simple explosive hand-grip

554 task with a cohort of male and female elite athletes. Prior to performance, they manipulated serious and

555 playful states and arousal by means of personalised guided imagery techniques and paced breathing.

556 Results showed that significant increases in strength performance occurred in the playful condition

557 when arousal was high and experienced as pleasant excitement (i.e., high positive arousal).

558 The imagery scripts used in this task were geared to the serious and playful states and may not have

559 induced equivalent mastery states in both the serious and playful versions. Careful consideration of the

560 example scripts, included by the authors, suggests that the serious script portrayed a lower level of

561 confidence than the playful script, which included descriptions of high self-confidence. This is

562 potentially a confounding factor.

563

Males et al. (1998) showed that the reported presence of serious and playful states varied at

564 different stages of canoe slalom competition. While the serious-conformist combination always

565 accounted for the majority of participants' self reports, playful-conformity was the second most

566 prevalent combination. The balance between the two varied according to the phase of the event.

567 Serious-conformity was highest between runs (84.4\%) and post-race (77\%), but playful-conformity

568 was highest during the race itself (35\%). Importantly, more than twice as many above- than below-

569 average performances occurred when participants reported the playful-conformist-self-focused-mastery

570 combination. In contrast, golf places very different demands on competitors compared with canoe

571 slalom. The duration is longer and it requires the consistent delivery of closed skills in a relatively

572 stable environment. Hudson and Walker (2002) found that successful golfers most frequently reported a

573 serious state during competition and went on to suggest, "The self-focused-serious-conformity

574 combination of motivational states is particularly prevalent in competitive sport and may facilitate 


\section{REVERSAL THEORY RESEARCH}

575 positive outcomes." (p. 213).

Kerr, Wilson, Bowling, and Sheahan (2005) used the TESI to explore pre- and post-game

577 emotions reported by female field hockey players over the course of a World Cup qualifying

578 tournament in which they played seven games with only one loss, in the first game.As the tournament

579 progressed and the team won its games, athletes were significantly more relaxed and excited after each

580 game in the tournament. Unpleasant emotion and stress results, associated with the loss of the first

581 game, significantly diminished as the team progressed to the tournament final. Given that both

582 relaxation (pleasant serious low arousal) and excitement (pleasant playful high arousal) were reported,

583 it is hard to draw clear conclusions on the serious and playful dimensions, other than to speculate that

584 both were salient at different times.

585 Research has examined players' responses before and after competition and found differences in

586 the emotional states of winning and losing rugby players (e.g., Kerr \& van Schaik, 1995; Wilson \&

587 Kerr, 1999). Interestingly, these studies identified few defining differences in participants' pre-event

588 emotions. The greatest differences emerged in the post-game responses ofplayers, when context (home

589 vs away games) and outcome appraisals (win vs loss) clearly had important roles in shaping emotional

590 responses. As might be expected, winning is generally associated with more pleasant emotions and

591 lower stress than losing. However, a study of Canadian and Japanese futsal players showed some cross-

592 cultural differences in the experience of winning and losing (Geisler \& Kerr, 2007). These studies offer

593 insight into the differing psychological demands on successful and unsuccessful athletes in the post-

594 event phase of competition, but are of limited value in identifying motivational states.

595 Research into recreational, rather than competitive, sport also provides a useful perspective.

596 Here performance can be assessed by the quality of the participant's experience and well-being rather

597 than by comparisons with others. Flow states of intense, focused peak experience are often considered

598 the sign of a successful performance in recreational and outdoor sports (Csikszentmihalyi \& 


\section{REVERSAL THEORY RESEARCH}

599 Csikszentmihalyi, 1988). Houge Mackenzie et al. (2011) explored the relationship between

600 motivational state and flow, and tested Rea's (1993, 2002) hypothesis that both serious and playful flow

601 states formed a dynamic pattern of experience that could be integrated into a state of "serious play".

602 Qualitative data showed that river-surfers reported two distinct forms of flow state, during which they

603 performed optimally. Playful flow accounts were described as sensation-oriented, exciting, playful

604 and/or undertaken without a clear outcome goal, whereas serious flow accounts identified a distinct

605 outcome goal or achievement focus (Houge Mackenzie et al., 2011).

\section{Critical Summary}

607 Considering RT performance research as a whole, there is no obvious correspondence that

608 relates motivational state to optimal performance. At times, performers can be successful when

609 operating with the serious or playful, conformist or negativistic states operative. Several studies have

610 found no relationship between performance outcome and the serious or playful states (e.g., Bindarwish

611 \&Tenenbaum, 2006; Thatcher et al., 2011). Therefore, the relationship between the serious and playful

612 states and performance based on current evidence is ambiguous. The mastery state emerges as a

613 potentially critical, if under-explored, performance factor. It is the most consistently reported state

614 during competition (e.g., Hudson \& Walker, 2002; Males et al., 1998), yet no published studies to date

615 have attempted to explore its components in detail. In RT terms, by the very nature of competitive

616 sport, participation and success should require the mastery state to be operative, as this provides the

617 motivational orientation towards seeking domination, power, and control over oneself (self-focused-

618 mastery), an opponent or team. Progression of this area of research would appear to be studies with

619 greater control, clearly specified hypotheses, effective measures and a research design that allows the

620 relationship between motivational states and performance to be accurately tested.

621 The present manuscript has reviewed research that identified and explored psychological

622 experience, as defined by RT, in the context of sport and exercise. Keeping in mind research limitations 


\section{REVERSAL THEORY RESEARCH}

623 pointed out in this review, the following somewhat tentative conclusions can be made about the four

624 main research themes:

625 1. Competitors' emotional and motivational experience in sport can be described, and mapped using the

626 full range of motivational states in RT.

627 2. Reversals in motivational state occur for the reasons suggested by RT, and this provides a

628 mechanism for understanding, predicting and influencing changes in an athlete's affective state.

629 3. Athletes and participants' individual dispositional personality factors can be accounted for through

630 the relationships that exist between motivational dominances and participation and experience of

631 different types of sport.

6324 . The relationship between motivational states (especially the serious and playful states) and

633 performance remains ambiguous.

634 In carrying out this narrative review, it became clear to the authors that, as with many bodies of

635 research, progress in RT research has not been logically sequential and research on different topics has

636 progressed at different rates over the years. As a result, there are a number of gaps in the RT sport and

637 exercise research literature that need to be addressed. One such gap exists in the use of RT to

638 understand exercise compliance and this could be the focus of a major future research project. Although

639 RT has made a contribution in terms of understanding the different motivational needs of exercisers

640 (e.g., through the Hong Kong studies), there is much more research that could be done. For example,

641 do people sustain and commit to exercise programs longer when it matches their motivational

642 dominance? Does monitoring changes in motivational state make it easier to adapt exercise regimes so

643 that they are more attractive to non-participants? For example, it should be possible to design exercise

644 programmes to move from a serious (telic) to a playful (paratelic) orientation, or vice versa. In

645 addition, RT should be able to help people who find it hard to sustain self-mastery during exercise and

646 drop out? Can these exercisers be "navigated" to self-sympathy when they need a break, preventing 


\section{REVERSAL THEORY RESEARCH}

647 them feeling guilty and giving up, then return them to self-mastery when required? The big strength of

648 RT is that helps to understand how and why motivation changes over time. This has not been fully

649 developed in RT exercise research so far. Results from RT smoking cessation research work (Cook,

650 Gerkovich, O’Connell, \& Potocky, 1995; O’Connell, 2006; O’Connell, Cook, Gerkovich, Potocky, \&

651 Swan, 1990), which applies the same principles in terms of giving up smoking is "good for you" yet

652 hard to do, may have implications for exercise. Likewise exercise is considered "good for you" and for

653 many people difficult to achieve. There are RT topics that have received little or no attention and a

654 great deal is still unknown: exercise compliance is one.

655 In some cases, research findings were limited by focusing exclusively on the serious-playful

656 pair. It is now clear that future studies should encompass all the motivational pairs to better account for

657 a broader range of sport and exercise experience. This notion was utilised to underpin a practical guide

658 for paddlers and coaches in canoeing and kayaking (Males, 2014), with potential applications to other

659 sport and exercise contexts. The guide refers to all the motivational states, but gives emphasis to

660 mastery-based motivation as providing the drive for athletes to challenge themselves and find the limits

661 of their ability.

662 Also, there is some research evidence supporting the causal factors for reversals, but there is

663 currently no academic research showing that reversals can be controlled, or that particular motivational

664 states can be reliably induced at will in the context of sport and exercise. The existing supporting

665 evidence for the conscious control of motivational states is largely anecdotal from practitioner activity

666 in sport. This is a limitation of RT sport and exercise research to date that must be addressed in the

667 future. For example, well-designed intervention studies using three participant groups under conditions

668 of : (a) an RT-based psychological intervention, (b) a non-RT psychological intervention and, (c) no

669 psychological intervention. A research design which utilised pre- and post-intervention measures plus

670 qualitative interview data could provide insightful results, directly relevant to applied intervention 


\section{REVERSAL THEORY RESEARCH}

671 work.

672 New research tackling these, and other topics (see Apter, 2013), could shape the future of RT

673 sport and exercise research. However, in order to facilitate the success of any future research, RT

674 researchers need to be open to obtaining the necessary insights into sport and exercise behaviour and

675 experience via a range of methodologies incorporating multiple data sources and possibly new

676 technology. For example, "smart phone apps" have the potential to gather an ongoing stream of

677 psychological and physiological data over time. Also, recent work on brain imaging is developing very

678 fast and reversals, as a result of motivational state manipulations, may be able to be recognised in

679 changing brain images. As with any research study, but especially for future RT studies, researchers

680 need to consider whether they are asking the "right" questions, using the appropriate methods, and have

681 tested the validity of measurement instruments developed in other fields in the context of sport and 682 exercise.

\section{Conclusion}

Although narrative reviews can be seen as less objective than systematic reviews, the authors made efforts to reduce the possibility of any publication bias by drawing attention to any methodological limitations and critical appraisal. Despite limitations and some gaps in the literature, past RT research has provided a good deal of important information. This has been useful for practitioners as well as researchers as RT has offered real insight that helps make sense of the psychological experience of athletes. Researchers have used the theory in a variety of different ways

690 (e.g., as a personality model, or for understanding stress, and as a basis for psychophysiological investigation) that have often made its phenomenological basis difficult to fully interpret. Recent

692 phenomenologically-based research (e.g., Grange \& Kerr, 2010; Houge Mackenzie \& Kerr, 2012)

693 appears to hold promise for understanding the complexity of the individual's sport and exercise 694 experience and might be an important direction for future research. There is reason for cautious 


\section{REVERSAL THEORY RESEARCH}

695 optimism regarding the future of reversal theory as a coherent psychological theory embracing

696 personality, emotion, and motivation with direct relevance to sport and exercise. However, there is a

697 need for additional robust research if this optimism is to be realised.

698

699

700

701

702

703

704 


\section{REVERSAL THEORY RESEARCH}

705

706

707

708

709

710

711

712

713

714

715

716

\section{References}

Apter, M. J. (1982). The experience of motivation: The theory of psychological reversals. London: Academic Press.

Apter, M. J. (2001). An introduction to reversal theory. In M. J. Apter (Ed.), Motivational styles in everyday life: A guide to reversal theory (pp. 3-35). Washington, DC: American Psychological Association.

Apter, M. J. (2013). Developing reversal theory: Some suggestions for future research. Journal of Motivation, Emotion and Personality, 1, 1-8.

Apter, M.J., \& Heskin, K. (2001). Basic research on reversal theory. In M. J. Apter (Ed.), Motivational styles in everyday life: A guide to reversal theory (pp. 77-96). Washington, DC: American Psychological Association.

Apter, M. J., Mallows, R., \& Williams, S. (1998). The development of the Motivational Style Profile. Personality and Individual Differences, 24, 7-18.

Apter, M. J., \& Svebak, S. (1989). Stress from the reversal theory perspective. In C. D. Spielberger \& J. Strelau (Eds.), Stress and anxiety, Vol. 12 (pp. 39-52). New York: Hemisphere.

Balague, G. (2005). Anxiety: From pumped to panicked. In S. Murphy (Ed.), The sport psych handbook (pp. 73-92). Champaign, Il: Human Kinetics.

Baumeister, R. F., \& Leary, M. R. (1997). Writing narrative literature reviews. Review of General Psychology, 1, 311-320.

*Bellew, E., \& Thatcher, J. (2002). Metamotivational state reversals in competitive sport. Social Behavior and Personality, 30, 613-624.

*Bindarwish, J., \& Tenenbaum, G. (2006). Metamotivational and contextual effects on performance, self-efficacy, and shifts in affective states. Psychology of Sport and Exercise, 7, 41-56. 


\section{REVERSAL THEORY RESEARCH}

728 *Blaydon, M. J., Lindner, K. J., \& Kerr, J. H. (2002). Metamotivational characteristics of eating729 disordered and exercise-dependent triathletes. Psychology of Sport and Exercise, 3. 223-236.

730 *Braathen, E. T., \& Svebak, S. (1990). Task-induced tonic and phasic EMG response patterns and 731 psychological predictors in elite performers of endurance and explosive sports. International 732 Journal of Psychophysiology, 9, 21-30.

733 *Braathen, E. T., \& Svebak, S. (1994). EMG response patterns and motivational styles as predictors of 734 performance and discontinuation in explosive and endurance sports among talented teenage 735 athletes. Personality and Individual Differences, 17, 545-556.

736 Brown, R. I. F. (2001). Addictions. In Apter, M . J. (Ed.) Motivational Styles in Everyday Life: A Guide 737 to Reversal Theory (pp. 155-165). Washington, D.C.: American Psychological Association.

738 Campo, M., Mellalieu, S., Ferrand, C., Martinent, G., \& Rosnet, E. (2012). Emotions in team contact 739 sports: A systematic review. The Sport Psychologist, 26, 62-97.

740 Carter, S., \& Davies, R. (2004). Management development in a motivationally rich environment. $741 \quad$ Industrial and Commercial Training, 36, 13-19.

742 *Chirivella, E. C., \& Martinez, L. M. (1994). The sensation of risk and motivational tendencies in 743 sports: An empirical study. Personality and Individual Differences, 16, 777-786.

$744 *$ Cogan, N., \& Brown, R. (1999). Metamotivational dominance, states and injuries in risk and safe 745 sports. Personality and Individual Differences, 27, 503-518.

746 Cook, M. R., Gerkovich, M. M., Potocky, M., \& O’Connell, K. A. (1993). Instruments for the 747 assessment of reversal theory states. Patient Education and Counselling, 22, 99-106.

748 Cook, M. R., Gerkovich, M. M., O’Connell, K. A., \& Potocky, M. (1995). Reversal theory constructs 749 and cigarette availability predict lapse early in smoking cessation. Research in Nursing \& Health, $750 \quad 18,217-224$. 


\section{REVERSAL THEORY RESEARCH}

751 752

753 754

755

*Cox, T., \& Kerr, J. H. (1989). Arousal effects during tournament play in squash. Perceptual and Motor Skills, 69, 1275-1280.

*Cox, T., \& Kerr, J. H. (1990). Cognition and mood in relation to the performance of squash tasks. Acta Psychologica, 73, 103-114.

Csikszentmihalyi, M., \& Csikszentmihalyi, I. S. (1988). Optimal experience: Psychological studies of flow in consciousness. Cambridge: Cambridge University Press.

Downing, L.H. (2000). How to do things with contradiction: Exploring humour in Joseph Heller's “Catch-22.” Atlantis, 22, 107-135.

Ekman, P. (1990). Basic emotions. In T. Dalgeish and M. Power (Eds.), Handbook of cognition and emotion (pp. 45-60). London, England: John Wiley \& Sons Ltd.

Fokkinga, S., \& Desmet, P. (2012). Meaningful mix or tricky conflict? A categorization of mixed emotional experiences and their usefulness for design. In J. Brassett, J. McDonnell, \& M. Malpass (Eds.), Out of Control:Proceedings of the 8th, International Conference on Design and Emotion, London, Saint Martins College of Art and Design.

Frijda, N. H. (1986). The emotions. Cambridge: Cambridge University Press.

Frijda, N. H. (1994). Varieties of affect: Emotions and episodes. Moods and sentiments. In P. Ekman \& R. J. Davidson (Eds.), The nature of emotion (pp. 59-67). Oxford, England: Oxford University Press.

*Frith, J. J., Kerr, J. H., \& Wilson. G. V. (2011) Immediate improvements in emotions and stress following participation in aerobics, circuit training and Tai Chi. International Journal of Sport Psychology, 42, 480-492.

*Fujiyama, H., Wilson, G. V., \& Kerr, J. H. (2005). Motivational state and emotional tone in baseball: The reciprocity between field research and reversal theory. European Review of Applied Psychology, 55, 71-83. 


\section{REVERSAL THEORY RESEARCH}

$775 *$ *Geisler, G., \& Kerr, J. H. (2007). Competition stress and affective experiences of Canadian and

$776 \quad$ Japanese futsal players. International Journal of Sport Psychology, 38, 187-206.

777 Gerkovich, M. M. (1997). Understanding sexual risk-taking behavior. In S. Svebak \& M. J. Apter

778 (Eds.), Stress and health: A reversal theory perspective (pp. 131-142). Washington D.C.: Taylor \&

$779 \quad$ Francis.

780 *Grange, P., \& Kerr, J. H. (2010). Physical aggression in Australian football: A qualitative study of elite $781 \quad$ athletes. Psychology of Sport and Exercise, 11, 36-43.

782 Hanton, S., Wadey, R., \& Connaughton, D. (2005). Debilitative interpretations of competitive anxiety: 783 A qualitative examination of elite performers. European Journal of Sport Sciences, 5, 123-136.

784 *Houge Mackenzie, S., Hodge, K., \& Boyes, M. (2010). A positive learning spiral of skill development 785 in high-risk recreation: Reversal theory and flow. Journal of Experiential Education, 32, $285-289$.

786 *Houge Mackenzie, S., Hodge, K., \& Boyes, M. (2011). Expanding the flow model in adventure 787 activities: A reversal theory perspective. Journal of Leisure Research, 43, 519-544.

788 *Houge Mackenzie, S., Hodge, K., \& Boyes, M. (2013). The multiphasic and dynamic nature of flow 789 in adventure experiences. Journal of Leisure Research, 45, 214-232.

790 *Houge Mackenzie, S., \& Kerr, J. H. (2012). A (mis)guided adventure tourism experience: An 791 autoethnographic analysis of mountaineering in Bolivia. Journal of Sport and Tourism, 17, $125-$ 792144.

*Houge Mackenzie, S., \& Kerr, J. H. (2014). The psychological experience of river guiding: Exploring the protective frame and implications for guide wellbeing. Journal of Sport and Tourism, 19, 527.

793 Howard, R.C. (2011). The question of excitement: A missing link between personality disorder and 794 violence? Journal of Forensic Psychiatry and Psychology, 22, 692-705.

795 *Hudson, J., \& Bates, M. D. (2000). Factors affecting metamotivational reversals during motor task 


\section{REVERSAL THEORY RESEARCH}

performance. Perceptual and Motor Skills, 91, 373-384.

*Hudson, J., \& Walker, N. C. (2002). Metamotivational state reversals during matchplay golf: An

798 idiographic approach. The Sport Psychologist, 16, 200-217.

799

800

801

802

803

804

805

806

807

808

809

810

811

812

813

814

815

816

John, O. P., \& Gross, J. J. (2004). Healthy and unhealthy emotion regulation: Personality processes, individual differences, and life span development. Journal of Personality, 72, 1301-1334.

Jones, G. (1995). More than just a game: Research developments and issues in competitive anxiety in sport. British Journal of Psychology, 86, 449-478.

Jones, G., \& Hanton, S. (2001). Pre-competitive feeling states and directional anxiety interpretations. Journal of Sport Sciences, 19, 385-395.

Jones, R. S. P., \& Heskin, K. J. (1988). Towards a functional analysis of delinquent behaviour: A pilot study. Counselling Psychology Quarterly, 1, 35-42.

Kerr, J. H. (1985). The experience of arousal: A new basis for studying arousal effects in sports. Journal of Sports Sciences, 3, 169-179.

*Kerr, J. H. (1987). Differences in the motivational characteristics of 'professional,' 'serious amateur' and 'recreational' sports performers. Perceptual and Motor Skills, 64, 379-382.

*Kerr, J. H. (1991). Arousal-seeking in risk sport participants. Personality and Individual Differences, $12,613-616$.

Kerr, J. H. (1997). Motivation and emotion in sport: Reversal theory. Hove, England: Psychology Press.

Kerr, J. H. (2001). Counselling athletes: Applying reversal theory. London: Routledge.

Kerr, J. H., \& Apter, M. J. (1999). The State of Mind Indicator for Athletes. In J. H. Kerr (Ed.), Experiencing sport: Reversal theory (pp. 239-244). Chichester, England: Wiley Publications.

*Kerr, J. H., Au, C. K. F., \& Lindner, K. J. (2004). Motivation and level of risk in male and female recreational sport participation. Personality and Individual Differences, 37, 1245-1253. 


\section{REVERSAL THEORY RESEARCH}

820 *Kerr, J. H., \& Cox, T. (1988).Effects of telic dominance and metamotivational state on squash task

821 performance. Perceptual and Motor Skills, 67, 171-174. check 1988 is listed in text

822 *Kerr, J. H., \& Cox, T. (1990). Cognition and mood in relation to the performance of a squash task.

$823 \quad$ Acta Psychologica, 73, 103-114.

824 Kerr, J. H., \& de Kock, H. (2002). Aggression, violence, and the death of a Dutch soccer hooligan: A

825 reversal theory explanation. Aggressive Behavior, 28,1-10.

826 *Kerr, J. H., Fujiyama, H., \& Campano, J. (2002). Emotion and stress in serious and hedonistic leisure

827 sport activities. Journal of Leisure Research, 34, 272-289.

828 *Kerr, J. H., Fujiyama, H., Sugano, A., Okamura, T., Chang, M., Onouha, F. (2006). Psychological

829 responses to exercising in laboratory and natural environments. Psychology of Sport and Exercise,

$830 \quad 7,345-359$.

831 *Kerr, J. H., \& Houge Mackenzie, S. (2012). Multiple motives for participating in adventure sports.

832 Psychology of Sport and Exercise, 13, 649-657.

833 *Kerr, J. H., \& Houge Mackenzie, S. (2014). Confidence frames and the mastery of new challenges in

834 the motivation of an expert skydiver. The Sport Psychologist, 28, 221-232.

835 *Kerr, J. H., \& Kuk, G. (2001). The effects of low and high intensity exercise on emotions, stress and 836 effort. Psychology of Sport and Exercise, 2, 173-186.

837 Kerr, J. H., Lindner, K. J., \& Blaydon, M. (2007). Exercise dependence. London, England: Routledge.

838 *Kerr, J. H., \& Males, J. R. (2010). The experience of losing: Qualitative study of elite lacrosse athletes 839 and team performance at a world championship. Psychology of Sport and Exercise, 11, 394-401.

840 *Kerr, J. H., \& Males, J. R. (2011). Experiencing aggression in sport: Insights from a lacrosse world 841 championship tournament. Sport and Exercise Psychology Review, 7, 26-33.

842 *Kerr, J. H., \& Svebak, S. (1989). Motivational aspects of preference for and participation in risk 843 sports. Personality and Individual Differences, 10, 797-800. 


\section{REVERSAL THEORY RESEARCH}

844 *Kerr, J. H., \& van Schaik, P. (1995). Effects of game venue and outcome on psychological mood state 845 in rugby. Personality and Individual Differences, 19, 407-410.

846 *Kerr, J. H., \& van den Wollenberg, A. E. (1997). High and low intensity exercise and psychological 847 mood states. Psychology \& Health, 12(5), 603-618.

848 *Kerr, J. H., \& Vlaswinkel, E. H. (1993). Self-reported mood and running under natural conditions. $849 \quad$ Work and Stress, 7, 161-177.

850 *Kerr, J. H., Wilson, G.V., Bowling, A., \& Sheahan, J. P. (2005). Game outcome and elite Japanese 851 women's field hockey players' experience of emotions and stress. Psychology of Sport and $852 \quad$ Exercise, 6, 251-263.

853 *Kerr, J. H., Wilson, G.V., Svebak, S, \& Kirkcaldy, B. D. (2006). Matches and mismatches between 854 telic dominance and type of sport: Changes in emotions and stress pre- to post-performance. 855 Personality and Individual Differences, 40, 1557-1567.

856 *Kuroda, Y., Thatcher, J., \& Thatcher, R. (2011). Metamotivational state and dominance: Links with 857 EMG gradients during isokinetic leg extension and a test of the misfit effect, Journal of Sports $858 \quad$ Sciences, 29, 403-41.

859 Lazarus, R. S. (2000). How emotions influence performance in competitive sports. The Sport $860 \quad$ Psychologist, 14, $229-252$.

861 Lazarus, R. S., \& Folkman, S. (1984). Stress, appraisal and coping. New York: Springer.

862 *Legrand, F. D., Bertucci, W. M., \& Thatcher, J. (2009). Telic dominance influences affective response 863 to a heavy-intensity 10-min treadmill running session. Journal of Sports Sciences, 27, 1059-1067.

*Legrand, F. D., \& Thatcher, J. (2011). Acute mood responses to a 15min-long walking session at self-selected intensity: Effects of an experimentally-induced telic or paratelic state. Emotion, 11, 1040-1045.

864 *Lindner, K. J., \& Kerr, J. H. (2000). Metamotivational orientations of sport participants and non- 


\section{REVERSAL THEORY RESEARCH}

865

866

867

868

869

870

871

872

873

874

875

876

877

878

879

880

881

882

883

884

885

886

887

888

participants. Psychology of Sport and Exercise, 1, 7-25.

*Lindner, K. J., \& Kerr, J. H. (2001). Predictability of sport participation motivation from metamotivational dominances and orientations. Personality and Individual Differences, 30, 759773.

Males, J. (2014). In the flow: Performance psychology for winning in canoeing and kayaking. Retrieved from www.smashwords.com

Males, J. R. (1999). Individual experience in slalom canoeing. In J. H. Kerr (Ed.), Experiencing sport: Reversal theory (pp. 189-208). Chichester, England: Wiley Publications.

*Males, J. R. \& Kerr, J. H. (1996). Stress, emotion and performance in elite slalom canoeists. The Sport Psychologist, 10, 17-37.

*Males, J. R., Kerr, J. H., \& Gerkovich, M. M. (1998). Metamotivational states during canoe slalom competition: A qualitative analysis using reversal theory. Journal of Applied Sport Psychology, $10,185-200$.

*Males, J. R., Kerr, J. H., Thatcher, J., \& Bellew, E. (2006). Team process and players’ psychological responses to failure in a national volleyball team. The Sport Psychologist, 20, 275-294.

Martens, R., Burton, D., Vealey, R. S., Bump, L. A., \& Smith, D. E. (1990). The Competitive State Anxiety Inventory - 2 (CSAI-2). In R. Martens, R. S. Vealey \& D. Burton (Eds.), Competitive anxiety in sport (pp. 117-190). Champaign, Il: Human Kinetics.

McDermott, M. R., \& Apter, M. J. (1988). The Negativism Dominance Scale. In M. J. Apter, J. H. Kerr, \& M. P. Cowles (Eds.), Progress in reversal theory (pp. 373-376). Amsterdam: Elsevier.

Murgatroyd, S. (1987). Humour as a tool in counselling and psychotherapy: A reversal theory perspective. British Journal of Guidance and Counselling, 15, 225-236.

Murgatroyd, S., Rushton, C., Apter, M. J., \& Ray, C. (1978). The development of the telic dominance scale. Journal of Personality Assessment, 42, 519-528. 


\section{REVERSAL THEORY RESEARCH}

889 Nettle, D. (2007). Personality: What makes you the way you are. Oxford: Oxford University Press.

890 O’Connell. K. (2006). Reversal theory states and cigarette availability predict lapses during smoking 891 cessation among adolescents. Research in Nursing and Health, 26, 4, 263-271.

892 O’Connell, K. A., Cook, M. R., Gerkovich, M. M., Potocky, M., \& Swan, G. E. (1990). Reversal theory 893 and smoking: A state-based approach to ex-smokers' highly tempting situations. Journal of 894 Consulting and Clinical Psychology, 58, 489-494.

895 *Pain, M., \& Kerr, J. H. (2004). Continued participation in risk sport despite serious injury. British 896 Journal of Sports Medicine, 38, 337-339.

897 *Perkins, D., Wilson, G. V., \& Kerr, J. H. (2001). The effects of elevated arousal and mood on maximal 898 strength performance in athletes. Journal of Applied Sport Psychology, 13, 239-259.

899 Potocky, M., Cook, M. R., \& O’Connell, K. A. (1993). The use of an interview and structured coding 900 system to assess metamotivational state. In J. H. Kerr, S. Murgatroyd \& M. J. Apter (Eds.), $901 \quad$ Advances in reversal theory (pp. 137-150). Amsterdam: Swets \& Zeitlinger.

902 Rea, D. W. (1993). Reversal theory explanations of optimal experience. In J. H. Kerr, S. Murgatroyd \& 903 M. J. Apter (Eds.), Advances in reversal theory (pp. 75-88). Amsterdam: Swets \& Zeitlinger.

904 Rea, D. W. (2002). Optimal motivation for talent development. Journal for the Education of the Gifted, $905 \quad 23,187-216$.

906 Rice, S. M., Purcell, R., De Silva, S., Mawren, D, Mcgorry, P. D., \& Parker, A. G.(2016). The mental 907 health of elite athletes: A narrative systematic review. Sports Medicine, 1-21. Retrieved from 908 springer.com/article/10.1007/s40279-016-0492-2. DOI: $10.1007 /$ s40279-016-0492-2

909 Rimehaug, T., \& Svebak, S. (1987). Psychogenic muscle tension: The significance of motivation and $910 \quad$ negative affect in perceptual-cognitive task performance.

911 International Journal of Psychophysiology, 5, 97-106. 


\section{REVERSAL THEORY RESEARCH}

912 Svebak, S. (1984). Active and passive forearm flexor tension patterns in the continuous perceptual-

913 motor task paradigm: The significance of motivation. International Journal of Psychophysiology,

$914 \quad 2,167-176$.

915 Svebak, S. (1986). Cardiac and somatic activation in the continuous perceptual-motor task: The

916 significance of threat and serious-mindedness. International Journal of Psychophysiology, 3, 155 -

$917 \quad 162$.

918 Svebak, S. (1990). Personality and sports participation. In G. P. H. Hermans \& W. L. Mosterd (Eds.), 919 Sports, medicine, and health (pp. 87-96). Amsterdam: Elsevier.

920 Svebak, S. (1993). The development of the Tension and Effort Stress Inventory (TESI). In J. H. Kerr, S. 921 Murgatroyd \& M. J. Apter (Eds.), Advances in reversal theory (pp. 189-204). Amsterdam, The $922 \quad$ Netherlands: Swets \& Zeitlinger.

923 Svebak, S. (1999). Links between motivational and biological factors in sport: A review. In J. H. Kerr 924 (Eds.), Experiencing sport: Reversal theory (pp. 129-151). West Sussex: John Wiley and Sons $925 \quad$ Ltd.

926 Svebak, S., Howard, R., \& Rimehaug, T. (1987). P300 and quality of performance in a forewarned 927 "Go-No Go" reaction time task: The significance of goal-directed lifestyle and impulsivity. 928 Personality and Individual Differences, 8, 313-319.

929 *Svebak, S., \& Kerr, J. (1989). The role of impulsivity in preference for sports. Personality and $930 \quad$ Individual Differences, 10, 51-58.

931 Svebak, S. \& Murgatroyd, S. (1985). Metamotivational dominance: A multi-method validation of 932 reversal theory constructs. Journal of Personality and Social Psychology, 48, 107-116.

933 Svebak, S., Storfjell, O., \& Dalen, K. (1982). The effect of a threatening context upon motivation and 934 task-induced physiological changes. British Journal of Psychology, 73, 505-512.

935 *Thatcher, J., Kerr, J., Amies, K., \& Day, M. (2007). A reversal theory analysis of psychological 


\section{REVERSAL THEORY RESEARCH}

responses during sports injury rehabilitation. Journal of Sport Rehabilitation, 16, 343-362.

937 *Thatcher, J., Kuroda, Y., Thatcher, R., \& Legrand, F. D. (2010). Perceptual and cognitive responses

938 during exercise: Relationships with metamotivational state and dominance. European Journal of

$939 \quad$ Sport Science, 10, 199-207

940 *Thatcher, J., Kuroda, Y., Legrand F. D., \& Thatcher, R. (2011). Stress responses during aerobic

941 exercise in relation to motivational dominance and state, Journal of Sports Sciences. 29, 299-306.

942 *Thatcher, J., Reeves, S., Dorling, D., \& Palmer, A. (2003). Motivation, stress, and cortisol responses

943 in skydiving. Perceptual and Motor Skills, 97, 995-1002.

944 *Trimpop, R. M., Kerr, J. H., \& Kirkcaldy, B. (1999). Comparing personality constructs of risk-taking

945 behavior. Personality and Individual Differences, 26, 237-254.

946 Vera-Cruz, G., Vinsonneau, G., \& Mullet, E. (2010). Sexual permissiveness: A Mozambique-France 947 comparison. Journal of Applied Social Psychology, 40, 2488-2499.

948 *Vlaswinkel, E. H., \& Kerr, J. H. (1990). Negativism dominance in risk and team sports. Perceptual $949 \quad$ and Motor Skills, 70, 289-290.

950 Walters, J., Apter, M. J., \& Svebak, S. (1982). Colour preference, arousal and the theory of $951 \quad$ psychological reversals. Motivation and Emotion, 6,193-215.

952 Wilson, L. R. (2012). Reversal Theory: Understanding the Motivational Styles of Espionage.

953 International Journal of Intelligence Ethics, 3, 76-100.

954 *Wilson, G.V., \& Kerr, J. H. (1999). Affective response to success and failure: A study of winning and 955 losing in competitive rugby. Personality and Individual Differences, 27, 85-99.

956 Wilson, B., \& Wilson, L. L. (1996). Multiple selves operating within relationships. Journal of Family 957 Psychotherapy, 7, 41-51.

958 Zuckerman, M. (1979). Sensation seeking: Beyond the optimal level of arousal. Hillsdale: Erlbaum. 
REVERSAL THEORY RESEARCH 
REVERSAL THEORY RESEARCH

Table 1

Motivational State Combinations and the 16 Primary Emotions

Somatic emotions

\begin{tabular}{lll} 
State combination & Pleasant & Unpleasant \\
\hline serious-conformity & relaxation & anxiety \\
serious-negativism & placidity & anger \\
playful-conformity & excitement & boredom \\
playful-negativism & provocativeness & sullenness \\
\hline State combination & Pleasant & Transactional emotions \\
& & Unpleasant \\
\hline Self-focused-mastery & pride & humiliation \\
self-focused-sympathy & gratitude & resentment \\
other-focused-mastery & modesty & shame \\
other-focused-sympathy & virtue & guilt \\
\hline
\end{tabular}

